\title{
MANAGEMENT OF HIGH VELOCITY AND HIGH-ENERGY BLAST INJURIES TO THE MAXILLOFACIAL REGION AT NASSERR INSTITUTE
}

\author{
Niveen A. Askar
}

\begin{abstract}
Management of gunshot injuries to the face remains a cornerstone of the specialty of oral and maxillofacial surgery. Since the events of January 2011, the number of firearm related injuries has increased in Egypt, which was not the case since October 1973; this represented a challenge to both residents and experienced surgeons, owing to the complex nature of these injuries. The major types of gunshot injuries are blasts, either low order or high order explosives, high velocity and low velocity injuries. The severity of the injury depends on velocity, type of bullet and distance, resulting wounds could be penetrating, perforating or avulsive. The timing, sequence and prioritization of treatment remains the main areas of concern in the management of such complex cases. The following is the experience of the Maxillofacial Department at Nasser Institute in management of high velocity and high-energy blast Injuries to the maxillofacial region.18 cases of Maxillofacial gunshot injuries were admitted to Nasserr institute between January 2011 and October 2012 which was a time of street disturbances in Egypt, only nine patients met the criteria of selection suffering from high velocity injuries were included. Upon arrival, all patients underwent a primary survey and extensive clinical and radiographic examination, accordingly a treatment plan was set for each patient and surgical intervention there after according to the protocol we present. Based on our results and treatment outcome for all patients, we conclude that triaging gunshot injuries to a prepared trauma center, following a well-tailored protocol and the use of computer aided surgical simulation is an integral part to perfect the functional and esthetic outcome and treatment.
\end{abstract}

KEYWORDS: High velocity injuries, Blast injuries, Treatment protocol, Computer aided simulation

\section{INTRODUCTION}

Management of gunshot injuries to the face remains a cornerstone of the specialty of oral and maxillofacial surgery.

Since the events of January 2011, the number of firearm related injuries has increased in Egypt, which was not the case since October 1973; this represented a challenge to both residents and experienced surgeons, owing to the complex nature of these injuries.

\footnotetext{
* Associate Professor, Oral and Maxillofacial Department, Faculty of Dentistry, Cairo University
} 
The major types of gunshot injuries are blasts, either low order or high order explosives, high velocity and low velocity injuries. The severity of the injury depends on velocity, type of bullet and distance, resulting wounds could be penetrating, perforating or avulsive. ${ }^{1}$

Low velocity bullets: the projectiles possess only one third the kinetic energy of the high velocity bullets. Such bullets cause penetrating injuries, which inflict multiple fractures and lacerations and rarely involve avulsion. ${ }^{1}$

High velocity bullets creates a transient cavitation space with a small entrance wound and a much larger exit wound. This type of perforating injury is usually avulsive and causes enormous damage to soft and hard tissues and sever comminuation of the facial skeleton. ${ }^{2,3}$

Primary emergency treatment of high energy ballistic and blast injuries to the face, is done accordance to the advanced trauma life support (ATLS) guidelines, where airway management and control of bleeding represent the most important in triaging those patients who should be admitted to a level I trauma center, the success of management depends on timing, sequence and lines of treatment. ${ }^{4}$

Once patient condition is stabilized, a multidisciplinary approach for evaluation and proper imaging to achieve a detailed treatment plan and a prioritized sequence of surgical intervention, starting with lifesaving procedures control of bleeding, vascular surgery, reduction and fixation of open fractures, soft tissue primary closure if possible, should follow the emergency surgical intervention. ${ }^{5}$

Soft tissue and mid-facial reconstruction if needed should be done during the first week to obtain an optimum results, once the patient general condition is stabilized, while reconstruction of the mandible can be done later during the first month to allow for proper healing of the soft tissue and vascular bed for free bone grafting procedures. ${ }^{6,7}$
The following is the experience of the Maxillofacial Department at Nasser Institute in management of high velocity and high-energy blast Injuries to the maxillofacial region.

\section{PATIENTS AND METHODS}

18 cases of Maxillofacial gunshot injuries were admitted to Nasr institute between January 2011and October 2012, We excluded the superficial, soft tissue, and low velocity gunshot injuries, the 10 remaining patients, all males ( age range from 18 to 39 , mean 26.8 years) were suffering from high velocity injuries, 6 mandibular gunshot injuries and 4 maxillofacial blast injuries.

\section{Treatment Protocol:}

The following is the protocol of the maxillofacial department, Nasr institute in treatment of high velocity and high-energy blast injuries to the maxillofacial region: (figure1-4)

1. Primary emergency management (primary survey) following the ATLS recommendation: depending on the severity of the case Intubation upon arrival if required, cervical spine radiography, control of bleeding and hemodynamic stabilization.

Neurologic evaluation (Glasgow Coma Scale.) ${ }^{8}$

Tracheotomy and Percutaneous gastrostomy in highly avulsive and complex injuries might be needed in the operating room.

2. X-rays: computed tomography (CT) and 3-D $\mathrm{CT}$, angiography.

3. Comprehensive evaluation and diagnosis, formulation of a treatment plan and a prioritized sequence of surgical intervention.

4. Reduction, and establishing occlusion, and maxilla-mandibular relation (temporary immobilization). 
5. Early debridement and Soft tissue closure to establish optimum aesthetic result and provide full coverage and promote healing of the comminuted fracture, all traumatic tattoos, foreign bodes and non- viable tissues should be removed, irrigation and serial debridement every 48 hours for extensive contaminated wounds and Prophylactic antibiotics are mandatory to promote eventual healing under complete aseptic condition.

\section{Fracture Stabilization:}

* Restoration of the facial framework \& dimensions.

* Using the External pin fixation in comminuted injuries with minimal soft tissue damage.

- Internal plating if bone fragments large enough to accept screws.

- Establishment of mandibular continuity using reconstruction plate.

- Reestablishment of occlusion is the key point to create a useful anatomic platform.

- Arch bars and MMF is the mainstay of management of gunshot wound patients even if ORIF is used.

- If occlusion is not restored primarily it may never be the same afterwards.

\section{Primary Closure:}

- After skeletal fixation soft tissue coverage is crucial.

- Simple re-approximation and undermining of skin edges then closure without tension in most of the patients.

- In massive injuries soft tissue reconstruction using local or distant flaps are used either immediate or late depending on patient condition and treatment plan.

- Temporary coverage as galeal \& scalp flaps in case of late reconstruction.

8. Reconstruction of the facial skeleton using calvarial bone grafts if no contraindication, otherwise iliac crest bone grafting is the second choice.

9. Reconstruction of the comminuted mandible usually done during the first month using grafts from the iliac crest, using of free vascularized grafts in cases of massive avulsion of tissue or failure of primary reconstruction.

10. Use of computer aided simulation in cases need reconstruction whether during the first month of management of the case or late reconstruction, shorten the operating time, post-operative complications and optimize the functional and esthetic outcome. 


\section{Case 1:}

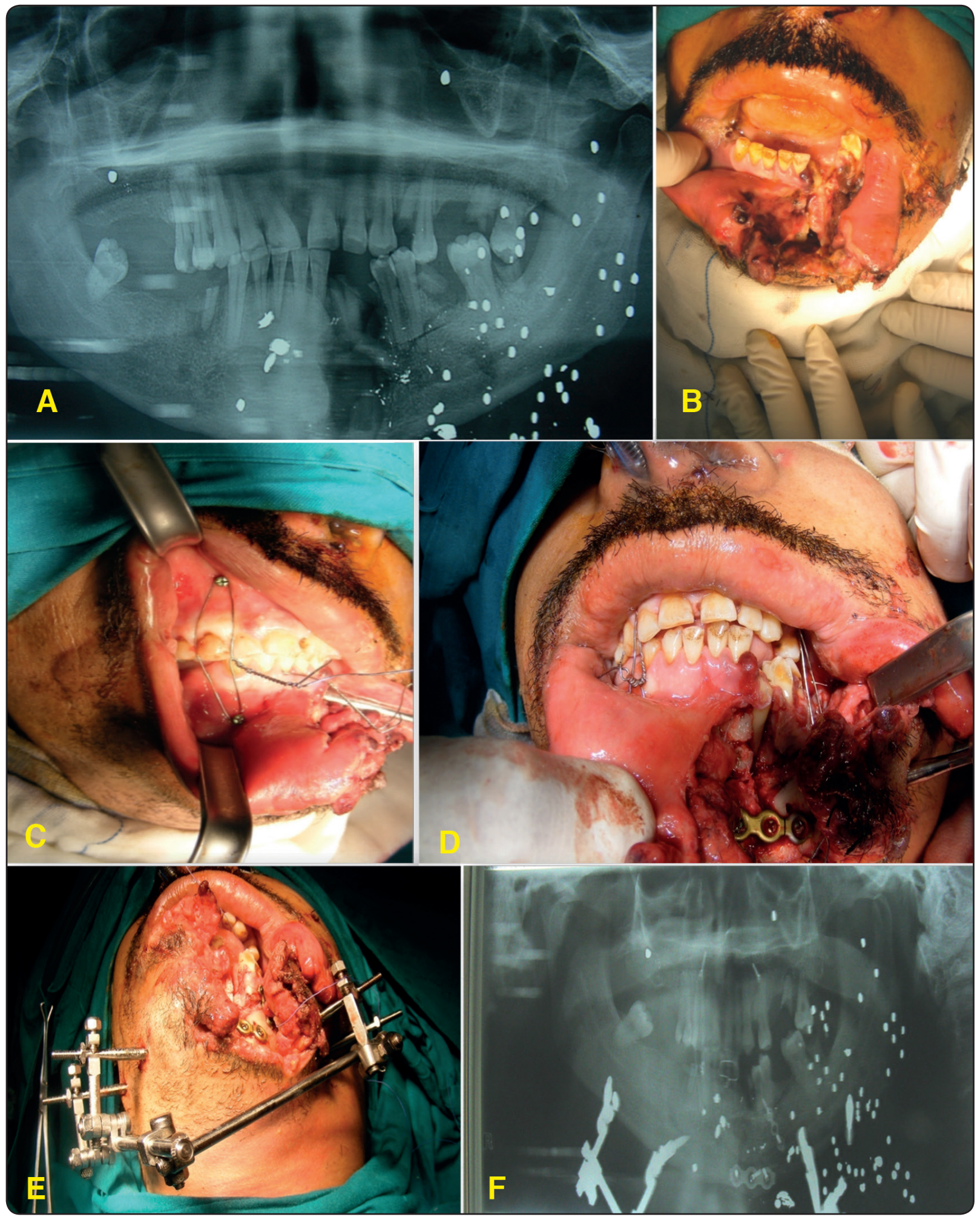




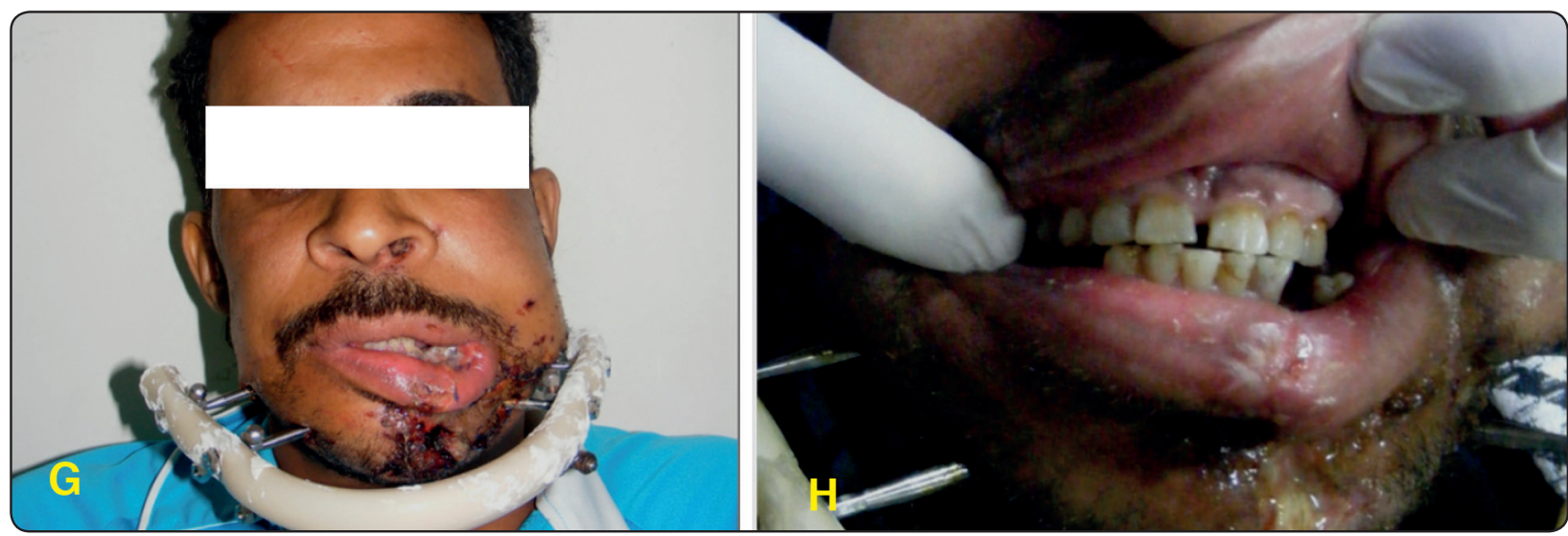

Figure1: case 1: (A) Preoperative panoramic x-ray showing parasymphyseal comminuated fracture $\&$ the presence of multiple shotgun pellets.(B) Preoperative photograph showing highenergy gunshot wound to the anterior mandible Note the soft and hard tissue disruption.(c) A photograph showing establishment of occlusion using skeletal screws to achieve MMF. (D) A photograph showing fracture reduction and fixation using internal plating. (E) Establishment of mandibular stability using external pin fixation and internal plate fixation.(F) A postoperative panoramic x-ray showing fracture reduction \& stabilization using external pin fixation and internal plating.(G) Immediate postoperative photograph showing skeletal stabilization using external pin fixation and primary closure of the facial wound.(H) One month postoperative photograph showing good occlusion and healing of the soft tissue wound.

\section{Case 2:}

\section{Blast injury}
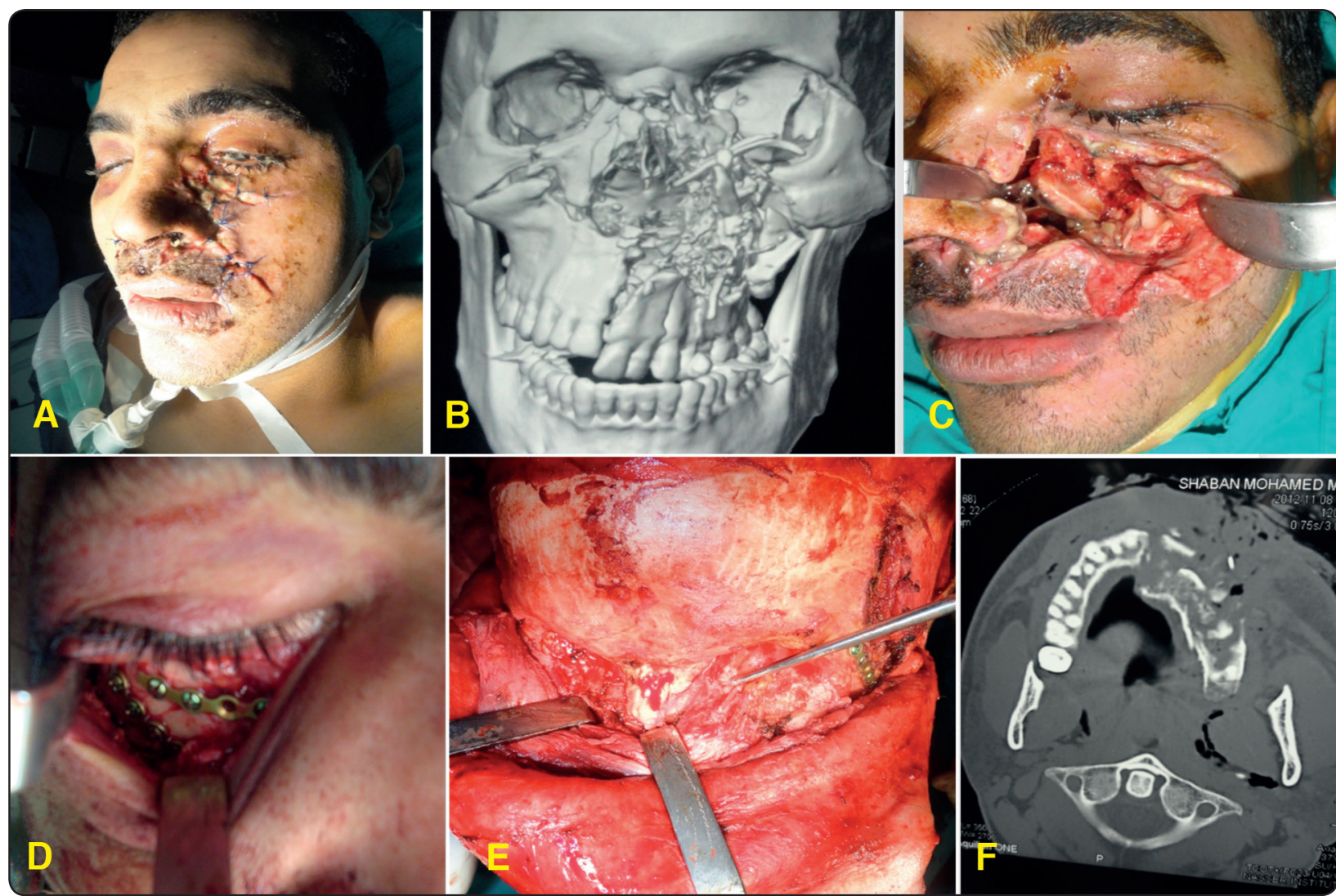

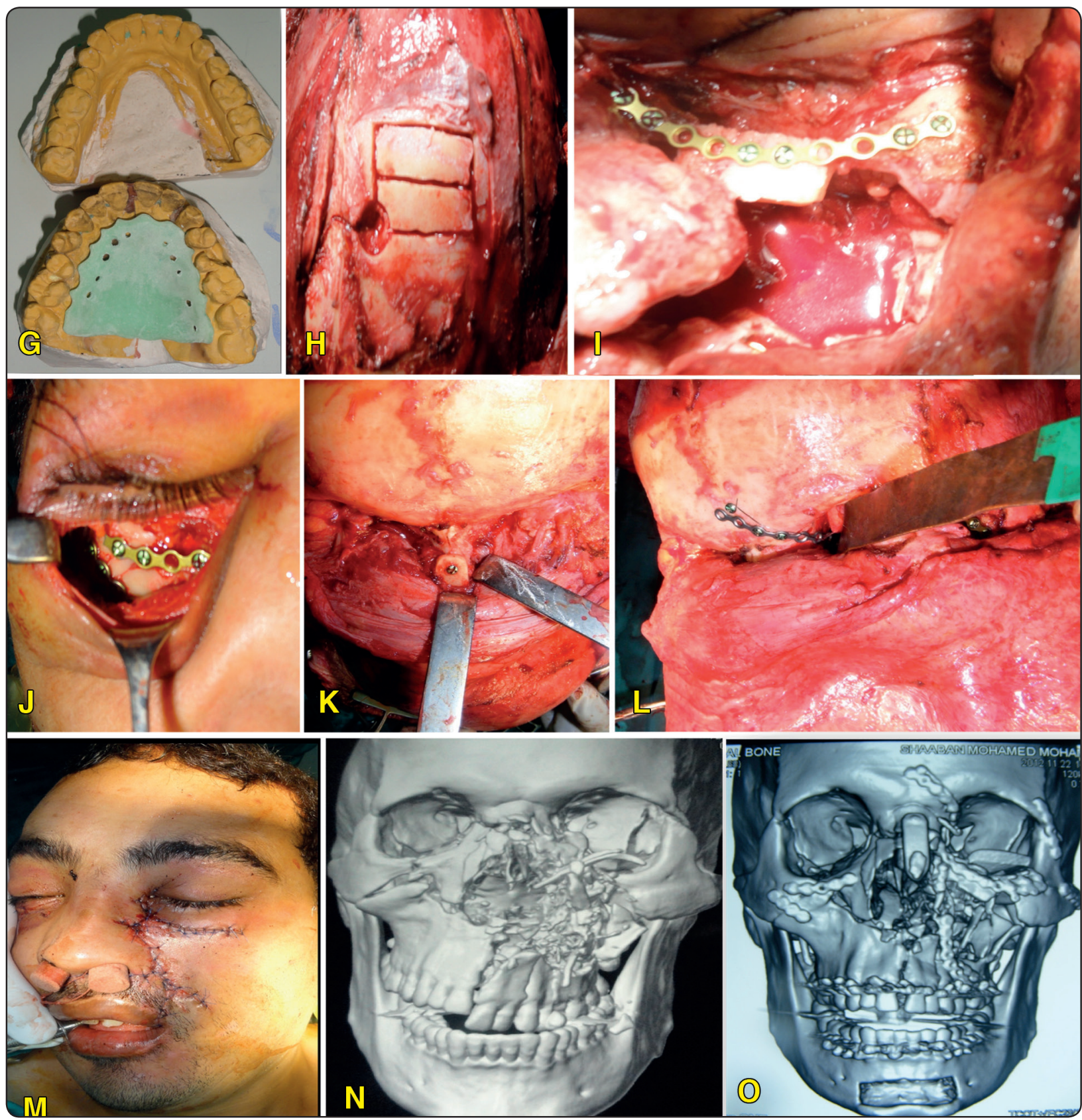

Figure2: case 2(A)Construction of Palatal Stent Guided by occlusion for reduction \& fixation of Palatal Fracture.(B) Calvarial Bone Harvesting.(C) Reconstruction of the inferior orbital rim and the floor of the orbit using the calvarial bone graft.(D) Reconstruction of the lateral nasal wall and anterior surface of maxilla using calvarial bone graft.(E) Reduction \& Fixation of the inferior orbital rim \& ZMC of the opposite side Reduction \& Fixation of the inferior orbital rim \& ZMC of the opposite side.(F) Nasal Reconstruction and fixation.(F) Medial Canthopexy. 


\section{Case 3:}
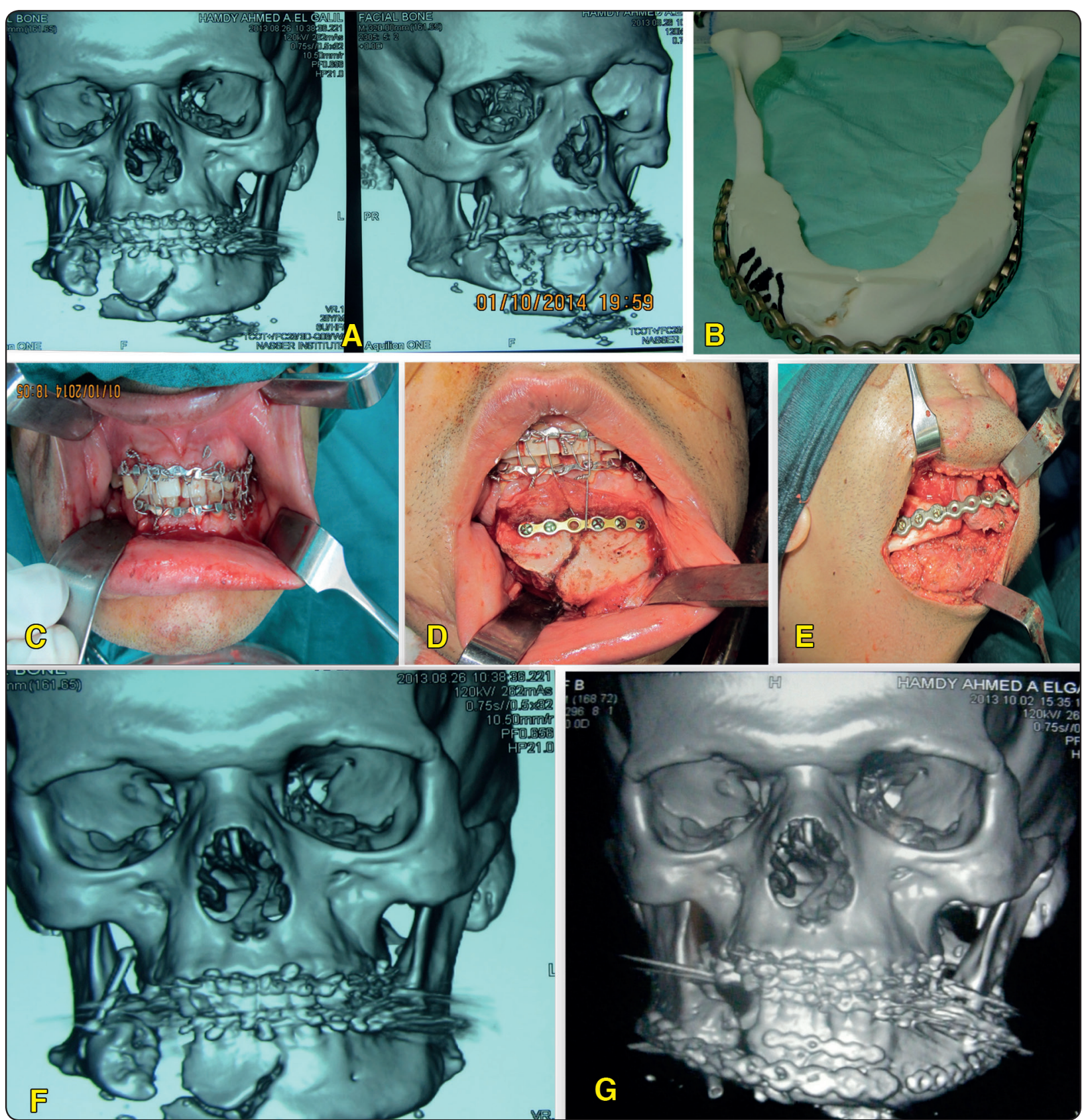

MAMDY AHMED A ELG

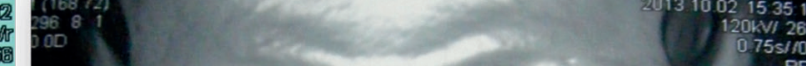

II

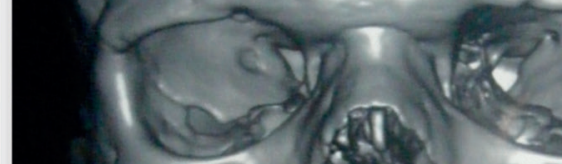




\section{Case 4:}

Late Reconstruction using computer aided simulation:

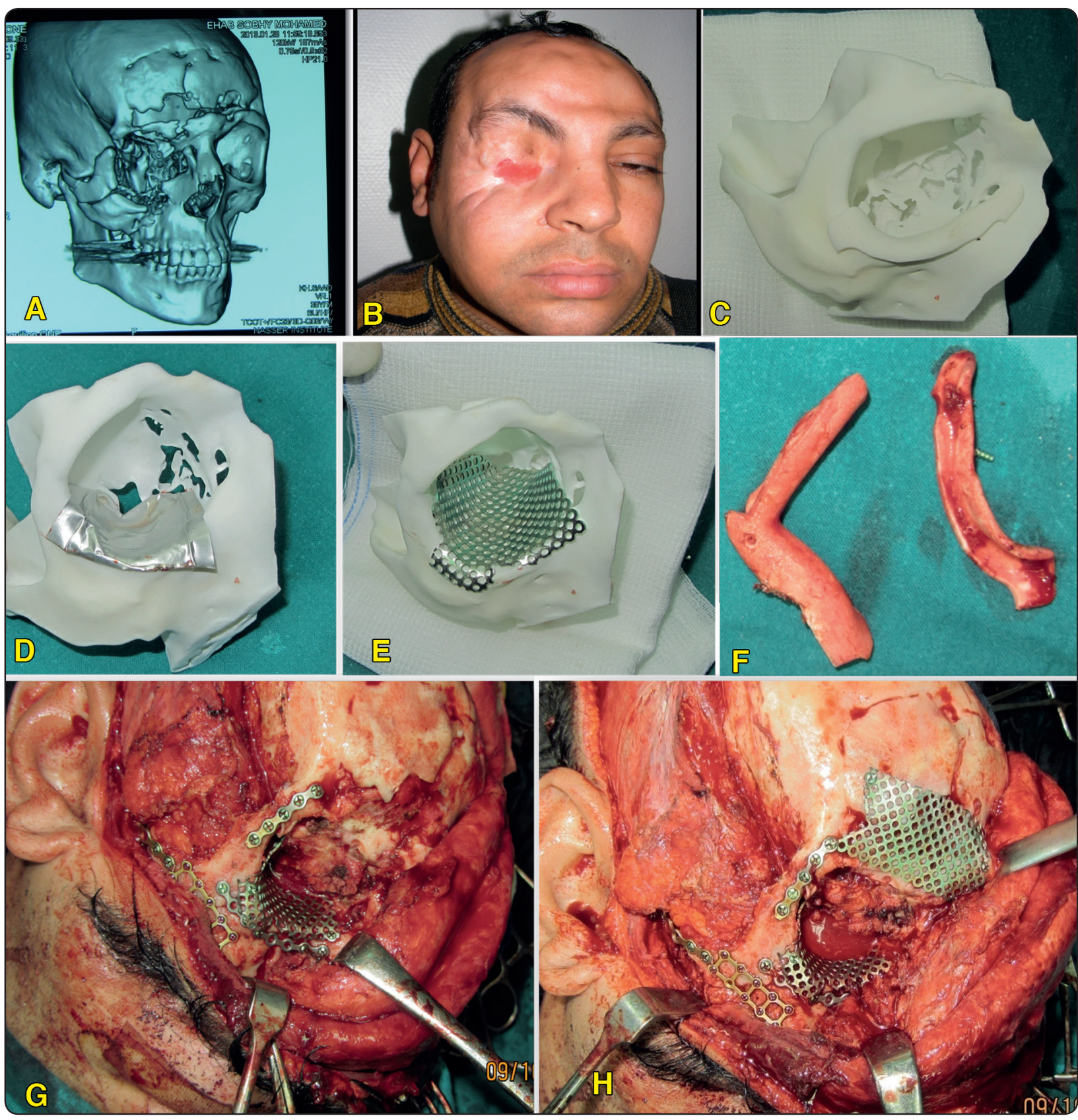




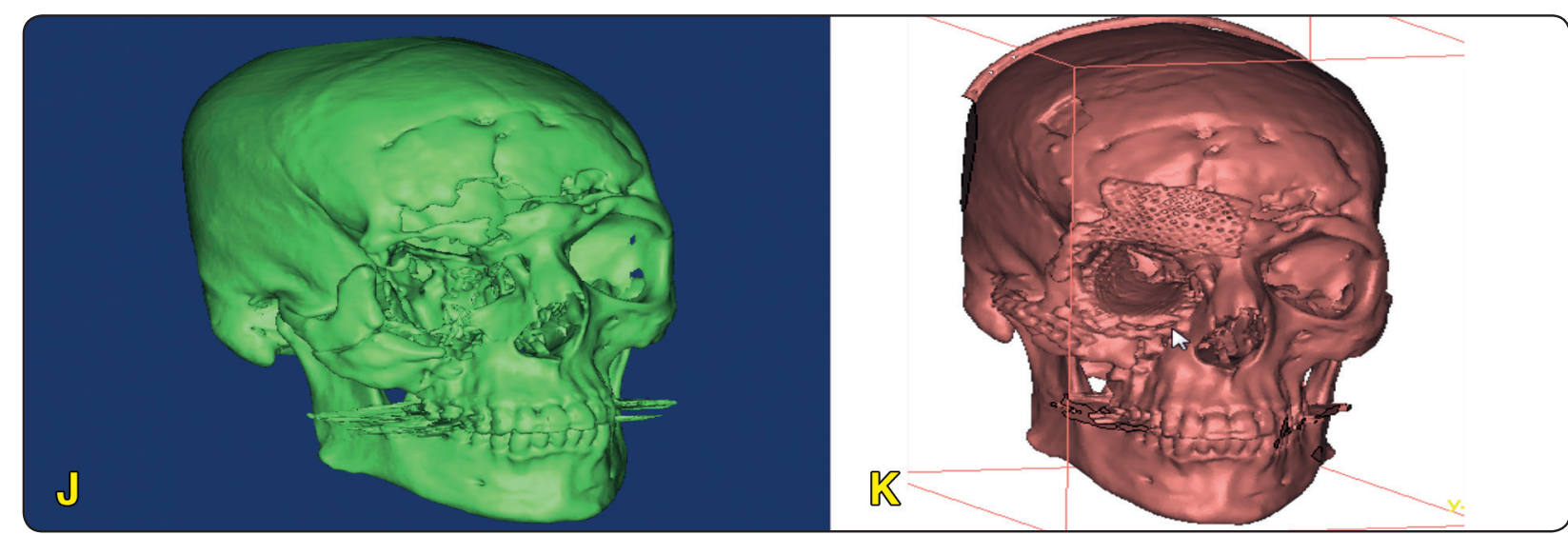

Fig. (4) Case 4 (A) Late Reconstruction using computer aided simulation. (B) Reconstruction of the Orbital cavity according to the template fixed in place using a screw to guide the reconstruction.(C) Photograph showing the reconstructed orbit and ZMC using plates and mesh.(D) A photograph showing reconstruction and fixation of the supraorbital rim and frontal bone using a mesh.(E) Preoperative . (F) Post-operative.

\section{RESULTS}

Out of 20 patients received in the above mentioned period, only 10 patients were included in this study group, none of them needed intubation or tracheostomy upon arrival as their Glasgow Coma scale was 15 .

All of them underwent primary survey and a complete clinical and radiographic examination upon arrival followed by a multidisciplinary treatment plan in poly-trauma cases.

The Emergency maxillofacial intervention was done in the same day of arrival, five cases underwent definitive treatment during the first two days of arrival, and the rest were treated one week after admission to the institute.

Establishing of occlusion using arch bars and internal plating to stabilize fracture was applied in all cases except two where External pin fixation because of sever commination, $2.0 \mathrm{~mm}$ and $1.5 \mathrm{~mm}$ was suitable for the cranium and mid-face fracture, while a more rigid $2.4 \mathrm{~mm}$ was used for the mandibular fractures, bone grafting was done in 4 cases, three using iliac bone for mandibular fracture and one calvarial bone for mid- face fracture.
Postoperative complications among the study group were wound dehiscence in two cases out of ten with a percentage of $20 \%$

Management was routine irrigation and oral hygiene measures associated with using of intravenous antibiotics. Healing went uneventful thereafter.

Patients stay at hospital ranged from 7 to 25 days with a mean of 8.5 day.

\section{DISCUSSION}

Management of ballistic high velocity and high energy injuries to the face requires a multidisciplinary approach received in level I trauma center for life saving and better esthetic and functional results after rehabilitation.

The present protocol of management of ballistic high velocity and high energy injuries to the maxillofacial region at Nassrr institute based on immediate primary survey of the patient upon arrival and accordingly providing all necessary life-saving procedures, including full radiographic and clinical evaluation of the patient, then a comprehensive priority treatment plan is tailored for each case , 
regarding the maxillofacial injuries, establishing of occlusion, stabilizing of fracture with rigid internal fixation with primary grafting if indicated, in sever comminuation external fixation is an option though rarely used now, primary soft tissue closure, and secondary grafting when indicated.( Fig1-4)

This protocol was implemented during the events in Egypt from2011 to2014, where incidents of gunshot and high velocity ballistic increased dramatically, and many of those victims were received and managed at Nassrr institute.

Based on the presented experience as well as others. ${ }^{5,-10}$ Primary definitive treatment of high velocity ballistic injuries results in better esthetic and functional results and decrease contracture of facial soft tissue and secondary scaring. This is in accordance with Peled et $\mathrm{al}^{9}$, who described a similar experience-based protocol include, a comprehensive multidisplinary approach and primary fracture stabilization, hard tissue reconstruction, grafting is needed and primary soft tissue closure whenever feasible.

Although, many advocates early definitive soft and hard tissue reconstruction, including the use of micro vascular free flaps ${ }^{11}$, we think that such intervention depends basically on the patient general condition and each case should be evaluated separately ,where in many cases such intervention should be postponed to a later stage, this also favoured by others ${ }^{9,12}$.

In the present study, we used external pin fixation in two cases, where sever comminuation and insufficient large bone fragments for plates fixation, it also allows preservation of blood supply to the area and promote healing of the bone fragments, this is in accordance with others ${ }^{9,13,14}$

We used internal rigid fixation in the rest of cases, micro and mini-plating was used for cranium and mid-face, a more rigid $2.4 \mathrm{~mm}$ was used for the mandible in most of the cases.
When primary bone grafting was performed, we used grafts from the iliac crest in two of mandibular fractures, which suits the reconstruction of the mandible regarding height and thickness, while grafting from cranium was performed in three cases, depending on the type of fractures, grafting from iliac crest, cranium and rib are all feasible options $^{9,14-15}$.

The relatively low complications rate in this series of cases might be attributed to the short interval between patient admission and surgical intervention and the fact that the institute is highly prepared to deal with such type of injuries, this in accordance with Peled et $\mathrm{al}^{9}$ who stressed on the importance of evacuating all cases of gunshot and blast injuries to a level I trauma center at the earliest time possible.

In all cases, surprisingly, a simple primary soft tissue closure was done by simple approximation and undermining of the wound edges and closure without tension. In more complicated cases, use of local, regional advancement flaps or distant free flaps is used, in all situations, establishment of primary soft tissue closure after thorough debridement along with fracture management optimize the functional and esthetic outcome in cases of gunshot injuries ${ }^{14-19}$.

The old trend of leaving the wound open even in complicated extensive penetrating wound usually resulted in scarring and complicate any further surgical intervention later and should be encouraged $^{4,7,18-20}$.

In the current series of cases, a computer aided simulation was implemented in one case of early reconstruction of the mandible, and another case of late reconstruction of the orbit and mid-face. In the recent years, using of such technology shorten significantly the operating time, increased the accuracy of reconstruction by simulating the reconstructed side to the unaffected one, which defiantly optimize the functional and esthetic outcome. 


\section{CONCLUSIONS}

- Patients are often in critical condition with sever concomitant injuries that have to be evaluated and stabilized before any reconstructive efforts.

- No strict protocol can be uniformly applied to all patients, the majority of Maxillo-facial penetrating injuries can be treated definitively at the time of debridement, the rest should be treated as soon as their general status permit.

- Establishment of occlusion and stabilization of the remaining skeletal framework and primary closure of the soft tissue if possible leads to the best functional and esthetic outcomes.

- Computer aided surgical simulation become an integral part in maxillofacial reconstruction to perfect the esthetic and functional outcome.

\section{REFERENCES}

1. Powers DB and Delo RI. Characteristics of Ballistic and Blast Injuries. Atlas Oral Maxillofacial Surg Clin N Am.21:15-24; 2013.

2. Clark N, Birely B, Manson PN, et al. High-energy ballistic and avulsive facial injuries: classifications, patterns, and an algorithm for primary reconstruction. Plast Reconst Surg .98(4):583-601; 1996.

3. Dimalo VJ. Gunshot wounds: practical aspects of firearms, ballistics, and forensic techniques. $2^{\text {nd }}$ edition. Washington, DC: CRC press;p.16-27;1999.

4. Kihtir T, Ivatury RR, Simon RJ, et al. Early management of civilian gunshot wounds to the face. J Trauma. 35:569$575 ; 1993$.

5. Denny AD, Sanger JR, Matloub HS, et al. Self-inflicted midline facial gunshot wounds: the case for a combined craniofacial and microvascular team approach. Ann Plast Surg.29:564-570; 1992.

6. Futran ND, Farwell DG, Smith RB, et al. Definitive management of sever facial trauma utilizing free tissue transfer. Otolaryngeal Head Neck Surg .132:75-85; 2005

7. Ozkan O, Ozgentas HE,Dikici MB. Simultaneous reconstruction of large maxillary and mandibular defects with a fibular osteocutaneous flap combined with an anterolateral thigh flap. J Reconst Microsurg .20:451-455; 2004

8. Demetriades $\mathrm{D}$, Chahwan $\mathrm{S}$, Gomez $\mathrm{H}$, et al. Initial evaluation and management of gunshot wounds to the face. J Trauma. 45:39-41;1998.

9. Peled M, Lesier Y, Emodi O, et al. Treatment protocol for high velocity/high energy gunshot injuries to the face. Uss Craniomaxillofac Trauma Reconstruction. 5:31-40; 2012

10. Gruss JS, Antonyshyn O, Phillips JH. Early definitive bone and soft tissue reconstruction of major gunshot wounds of the face. Plast Reconst Surg .87; 436-450; 1991

11. Tan YH, Zhou SX, Liu YQ, et al. Small-vessel pathology and anastomoses following maxillofacial firearm wounds: an experimental study. J Oral Maxillofac Surg. 49:348$352 ; 1991$

12. Suominen E, Tukiainen E. Close-range shotgun and rifle injuries to the face. Clin J Surg. 28:323-337; 2001

13. Ellis E, $3^{\text {rd }}$, Muniz O, Anand K. Treatment considerations for comminuted mandibular fractures. J Oral Maxillofac Surg. Aug; 61(8):861-70;2003

14. Gruss JS, Antonyshyn O, Phillips JH. Early definitive bone and soft-tissue reconstruction of major gunshot wounds of the face. Plast Reconst Surg. Mar;87(3):436-50;1991

15. Motamedi MH, Behnia H. Primary management of maxillofacial hard and soft tissue gunshot and shrapnel injuries. J Oral Maxillofac Surg. Dec;61(12):1390-8;2003

16. Motamedi MH, Behnia H. Experience with regional flaps in the comprehensive treatment of maxillofacial soft-tissue injuries in war victims. J Craniomaxillofac Surg. Aug; 27 (4):256-65; 1991

17. Motamedi MH. Primary treatment of penetrating injuries to the face. J Oral Maxillofac Surg. Jun; 65 (6):1215-8; 2007

18. Motamedi MH. Management of firearm injuries to the facial skeleton: Outcomes from early primary intervention. J Emerg Trauma Shock. Apr; 4 (2):212-6; 2011

19. Behnia H, Motamedi MH. Reconstruction and rehabilitation of short-range high velocity gunshot injury to the lower face: a case report. J Craniomaxillofac Surg. Aug; 25 (4):220-7; 1997.

20. Motamedi MH, Hashemi HM, Shams MG, et al. Rehabilitation of war-injured patients with implants: analysis of 442 implants placed during a 6-year period. J Oral Maxillofac Surg. Aug; 57 (8):907-13; 1999 